\title{
State of the environment around uranium mining sites (MIMAUSA: Memory and Impact of (French) Mining sites for urAniUm: Synthesis and Archives)
}

\author{
A.C. Servant, J . Herbelet and J .L. Daroussin* \\ Institut de Radioprotection et de Sûreté Nucléaire, BP. 17, \\ 92262 Fontenay-aux-Roses, France ( ${ }^{*}$ seconded from AREVA (COGEMA))
}

\begin{abstract}
In France, the mining and milling of uranium ore and the disposal of uranium mill tailings involved nearly 200 sites of very different nature. Being in charge of both the review of some remediation reports and the routine monitoring of the environment provides IRSN with selective data on most sites. The data collected by IRSN as well as those available from other data sources often remain incomplete therefore preventing IRSN from presenting a global view or answering some specific questions. In order to overcome this difficulty, it was decided, under the aegis of the Ministry of Ecology and Sustainable Development, that IRSN should develop a program of investigations organized in two parts: Part 1, called "State of knowledge " is aimed at assessing the amount of information available and at consolidating it into a user-friendly computerized database. The main goal is to identify the occurrence of significant enhanced radiological levels in the environment and to detect any lack of information concerning the various sites. This paper gives an overview of the information already collected. Part 2, called "specific studies" is aimed at fixing the gaps in the database by implementing new investigations on specific sites. It could lead to improvements in networks for the monitoring of radioactivity in the environment.
\end{abstract}

\section{INTRODUCTION}

France has been a major uranium producing country with COGEMA (AREVA group) as the main operator. Production was progressively reduced since 1988 and stopped in September 2001 when in Jouac (or Le Bernardan - Haute-Vienne) the mill delivered its last uranium concentrate (mine production had ceased in May). COGEMA has produced a large effort during the 90' to remediate the mining and industrial sites and is now responsible for the control and maintenance of nearly 200 sites located in 25 "departments" (administrative districts) of continental France.

The routine monitoring of the environment around these sites and the review of remediation projects reports concerning the disposal of tailings provide IRSN (Institute for Radiological Protection and Nuclear Safety) with selective data on most mining sites. However this information show that, in a certain number of cases, the past operations were responsible for enhanced radiological levels in the surrounding environment which are significant from a measurement point of view although they may not be significant in terms of public exposure and risks.

The data collected by IRSN as well as those available from other information sources often remain incomplete therefore preventing IRSN from presenting a global review or answering some specific questions, such as the anthropogenic or natural origin of radioactivity, as it is part of its core mission.

In order to overcome this difficulty, it was decided, under the aegis of the Ministry of Ecology and Sustainable Development, that IRSN should develop a program of investigations, the so called MIMAUSA program. MIMAUSA stands for "Memory and Impact of Mining sites for urAniUm: Synthesis and Archives”, it is a two fold project. The first part is an inventory of the existing uranium mining sites from which is extracted the information in this paper. 
To gather the detailed information necessary to fill the database, various archives were looked up: IRSN, DRIRE (Regional Direction for Industry, Research and Environment) but also, and for many updated details, COGEMA's Environmental Management System and archives. COGEMA has built a dedicated area in Bessines and has already filled 5.5 kilometres of shelves with the documentation produced, since 1948, from its worldwide mining involvement.

In addition to the Ministry of Ecology (MEDD-DPPR) and the organisations contributing with their archives, the steering committee also involves the Ministry of Industry (MINEFI-DARPMI), the Nuclear Safety Authority (DGSNR) and BRGM (office for the geological survey in France).

\section{THE INVENTORY: THE FORM AND SOME FACTS}

First edition of the inventory has been issued to the public in June 2004: see http://www.irsn.org. It has listed 186 sites operated from 1948 to 2001. They range from small exploration trenches or shallow mining works to large open cut or underground mines, also ore treatment plant (milling or heap leaching) and their disposal facilities as well as wastewater treatment units (see table 1).

For each site, twenty-four main items of information are grouped in a form such as in figure 1.

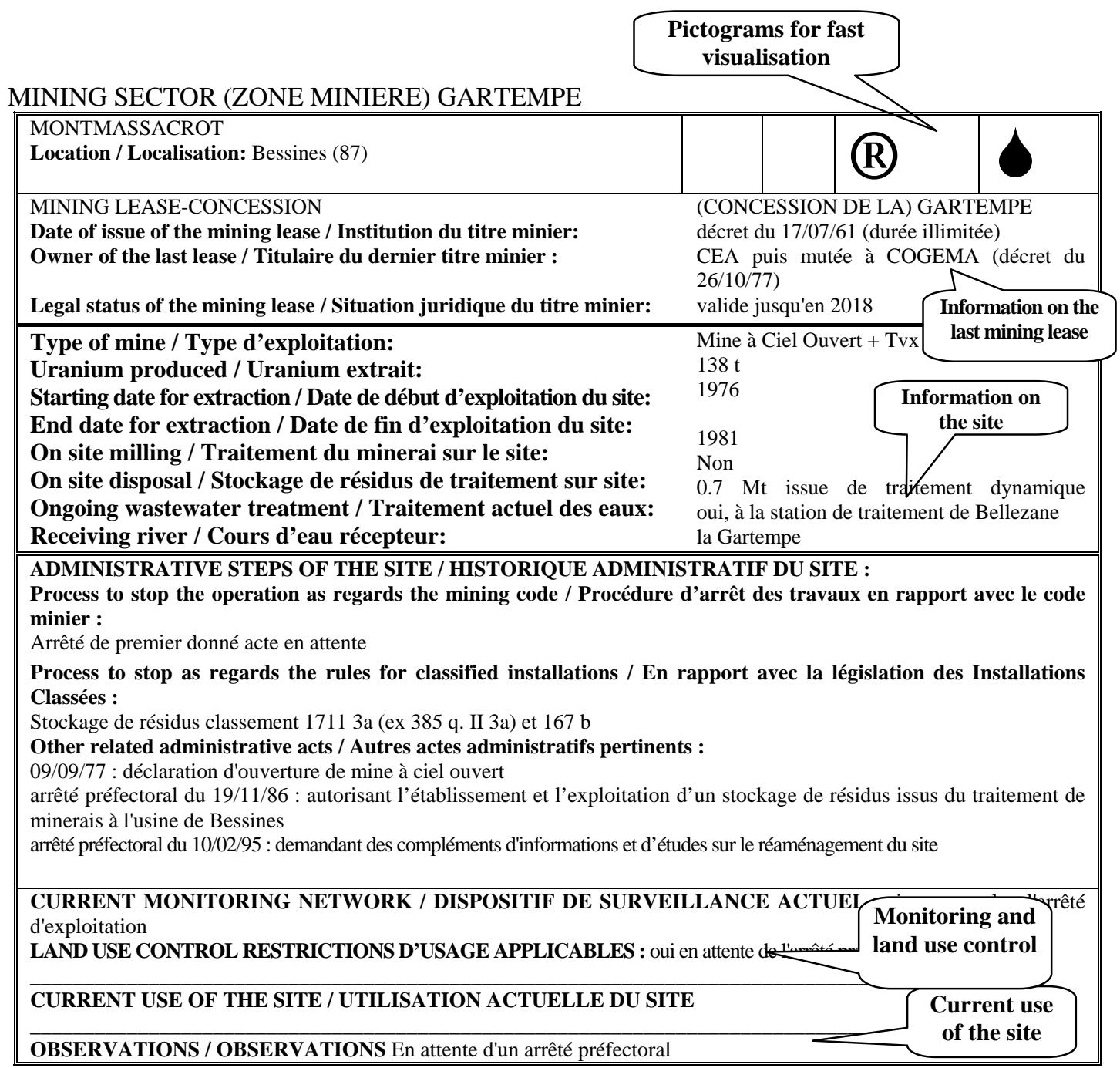


Figure 1. Example of a form of the national inventory of mining sites.

The following table gives an overview of the different categories of sites in the inventory.

Table 1. Overview of the sites.

\begin{tabular}{|l|c|}
\hline Total number of sites & 186 \\
\hline Total number of mining sectors & 22 \\
\hline Number of “départements" (French administrative district) & 25 \\
\hline Number of sites with only trenches or small mining works & 33 \\
\hline Number of sites hosting a mill & 8 \\
\hline Number of sites concerned with heap leaching & 11 \\
\hline Number of sites where one or more disposal facilities were operated & 16 \\
\hline Number of sites with ongoing waste water treatment (to achieve radiological and/or non radiological quality) & 13 \\
\hline
\end{tabular}

Excluding Le Bouchet

The total French production was 76000 tons of uranium in the concentrate (yellow cake). 160 million tons of waste rocks are stored on the mining sites and 48 million tons of solid uranium mill tailings and heap leaching residues are stored in 16 disposals (four of them group more than $86 \%$ of all the wastes from uranium treatment in France namely, the industrial site of Bessines (Haute-Vienne), the sites of L’Ecarpière (Loire-Atlantique and Maine-et-Loire), Le Bosc (Hérault) and Le Cellier (Lozère).

The diagrams presented in this paper are mostly prepared on the basis of the information gathered for the inventory. To date, more than 90-95\% of most of the items listed in the form presented in figure. 1 have been answered.

Usually, facts and data have been found easily. More difficult is to get the information regarding mine closure especially for the oldest ones, as the process did not include any written statement.

\subsection{The mining sectors}

The term "Mining sector" has been defined on purpose for the inventory. Twenty-two of them have been identified (see Figure ): they have been used during the mining operations to design groups of sites in the same area.

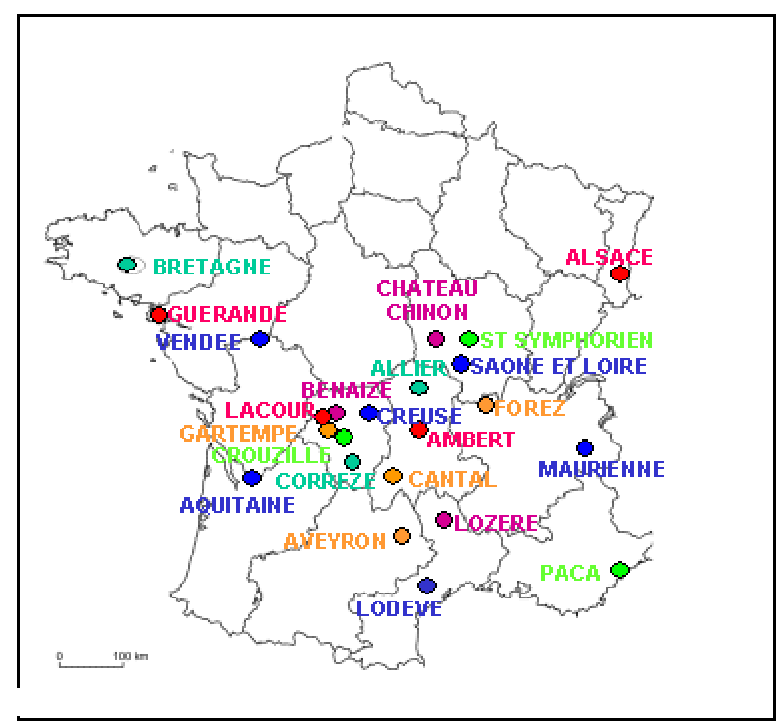

Figure 2. Location of the 22 mining sectors of the inventory. 


\subsection{The mining leases}

"Mining lease" stands for any type of right given according to the mining code, either right to explore (exploration licence - PER is the French acronym) or to mine for different periods of time (extraction mining lease - PEX - or mining lease-concession - Concession -).

The inventory provides the type and legal status of the last mining lease where each site is located in. According to figure 3, only 29 mining lease-concessions are still valid.
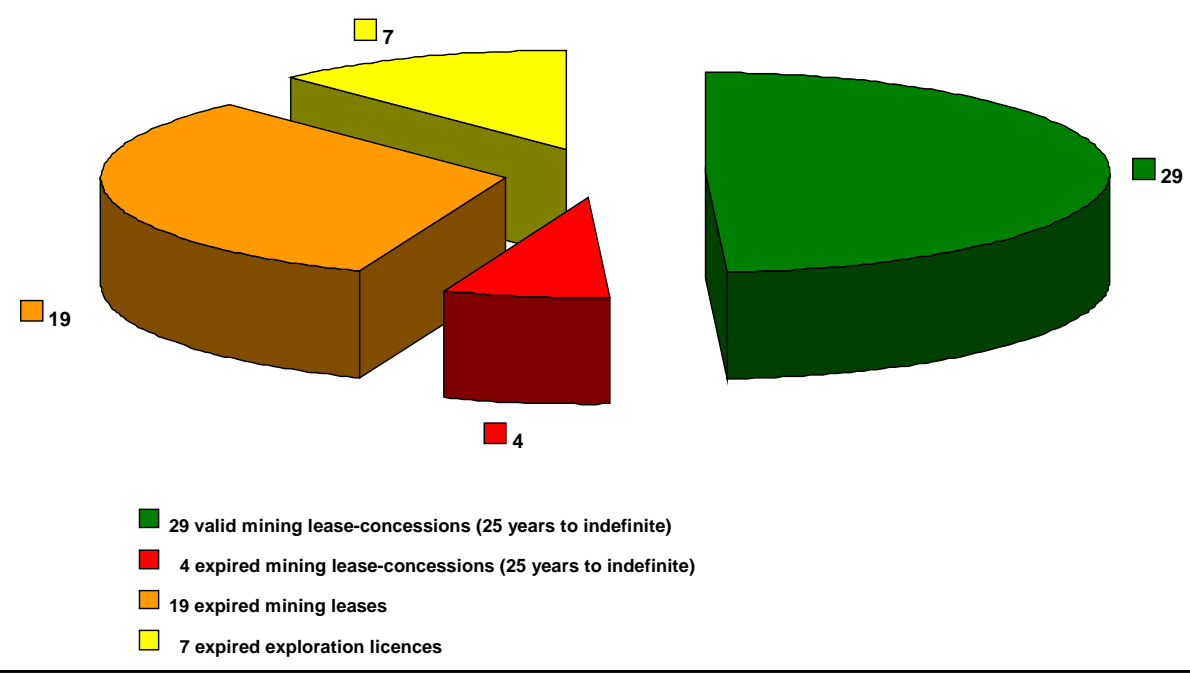

Figure 3. Last type of mining lease (where site was located).

\subsection{Size of the sites}

The size considered is not the area extension of the site but its uranium output: this is directly linked to the grade and amount of ore produced.

Out of the 186 sites, $20 \%$ have produced nearly no uranium at all because they led only to "exploration" work such as trenches or small mining works (so called "travaux de reconnaissance par petits chantiers" or TRPC).

Figure 4 shows the distribution of sites according to their uranium production. Notice that:

- Nearly $40 \%$ of the sites produced less than 10 tons of uranium;

- $9 \%$ of the sites produced more than 1000 tons uranium and their total production is almost $85 \%$ of nearly 80000t mined in France (Bernardan, Brugeaud, Bellezane, Fanay, Fraisse, Margnac-Pény, Bois Noirs Limouzat, Lodève, St Pierre du Cantal, La Besse, Ecarpière, Commanderie, Chardon, Les Pierres Plantées, Cellier). 


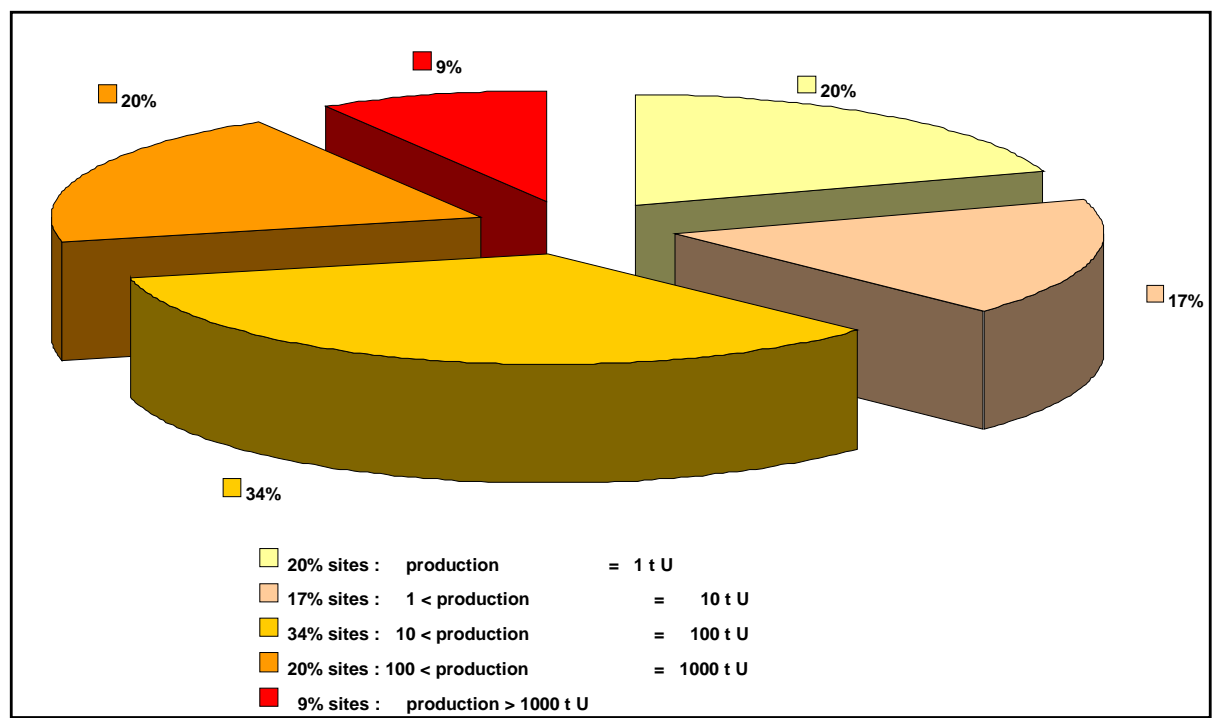

Figure 4. Distribution of sites according to their uranium production.

\subsection{Site monitoring}

The monitoring status of the sites is various (see figure 5).

All together more than $60 \%$ of the sites are still controlled.

Mill tailings disposals are all, except one, monitored by COGEMA: in such case, ambient gamma irradiation, air and/or water, and/or biota are measured or sampled and analysed. For the last mentioned site, La Ribière, after several years of monitoring, a licence allowed the operator to stop it.

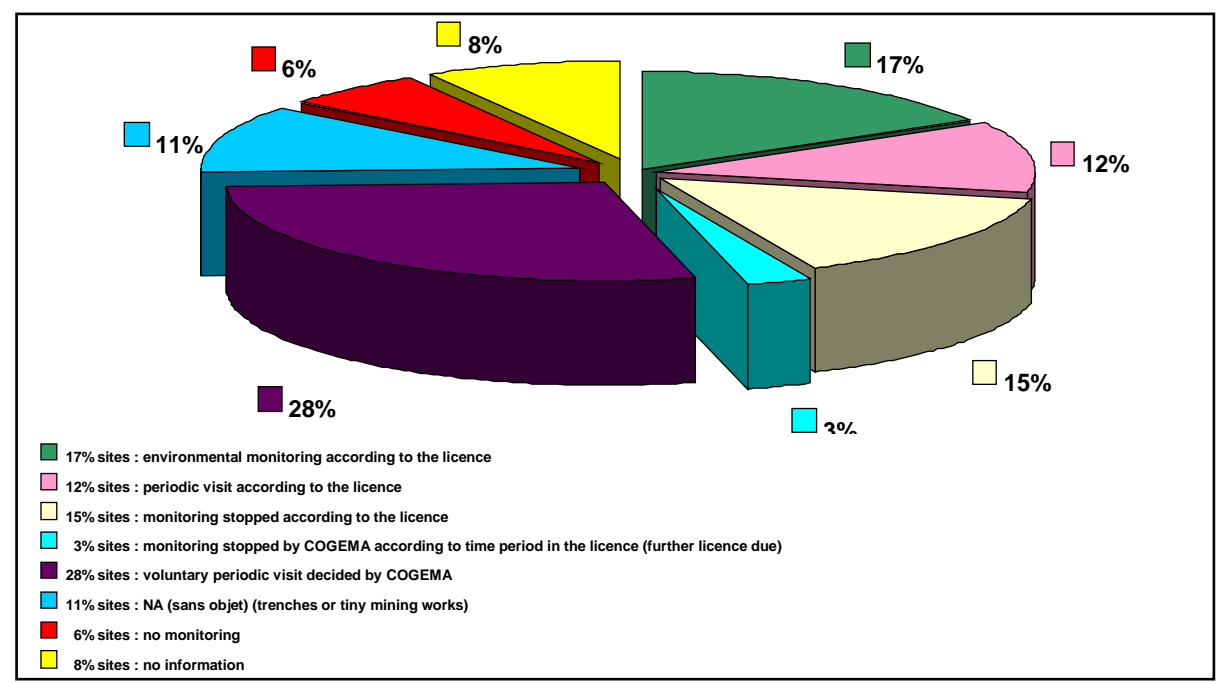

Figure 5. distribution of sites according to their monitoring status. 


\subsection{Restriction in the land use control}

The licences prescribe restrictions on the right of use for all mill tailings disposal sites. For several sites however they are not yet fully completed because not yet registered in the judicial mortgage.

The distribution of sites as regards use limitations is shown in figure 6.

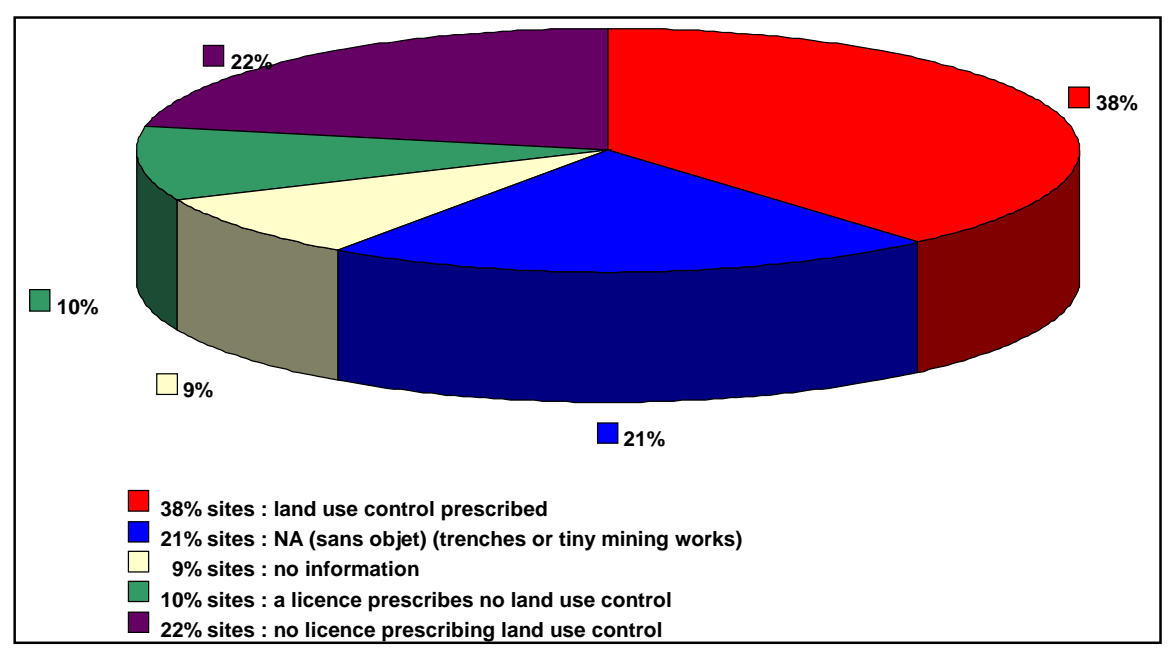

Figure 6. Distribution of sites according to limitations on current land use control.

Nearly $40 \%$ of all sites have been licensed with limitations of the land use. Most of them are on site building restrictions (because the site is a disposal for mill tailings or due to potential instability linked to the mining). Drilling is also forbidden specially in case of potential water quality concern.

\subsection{Status at the end of operation}

At the end of the mining operations, the notification process according to the mining code has changed with time.

Before modification of the mining code in 1995, the process was either a declared voluntary abandon of a mining site (or "délaissement" - $28 \%$. The site has then still to be controlled by the operator), or an abandon of a mining site after remediation which had been agreed by the administration (22\%).

In those two cases, this could be the result of a simple exchange of letters between the operator and the administration (DRIRE).

Nowadays (32\%), there is a two steps remediation work which ends by licensing: this means that the administration gives an agreement on a remediation project ("1er donné acte") and, following implementation of the project (including added specifications), the final licence is issued ("2ème donné acte"): this licence may prescribe monitoring. The inventory has no information yet regarding some sites and their status (11\%).

In some cases the licence content has not been consulted yet (3\%) or the licence is still under examination by the administration (4\%).

Following figure 7 shows the distribution of the various statuses of the sites at the end of operation. Notice that, because many sites have stopped operating for a long time, $50 \%$ are abandoned following the former procedures. 


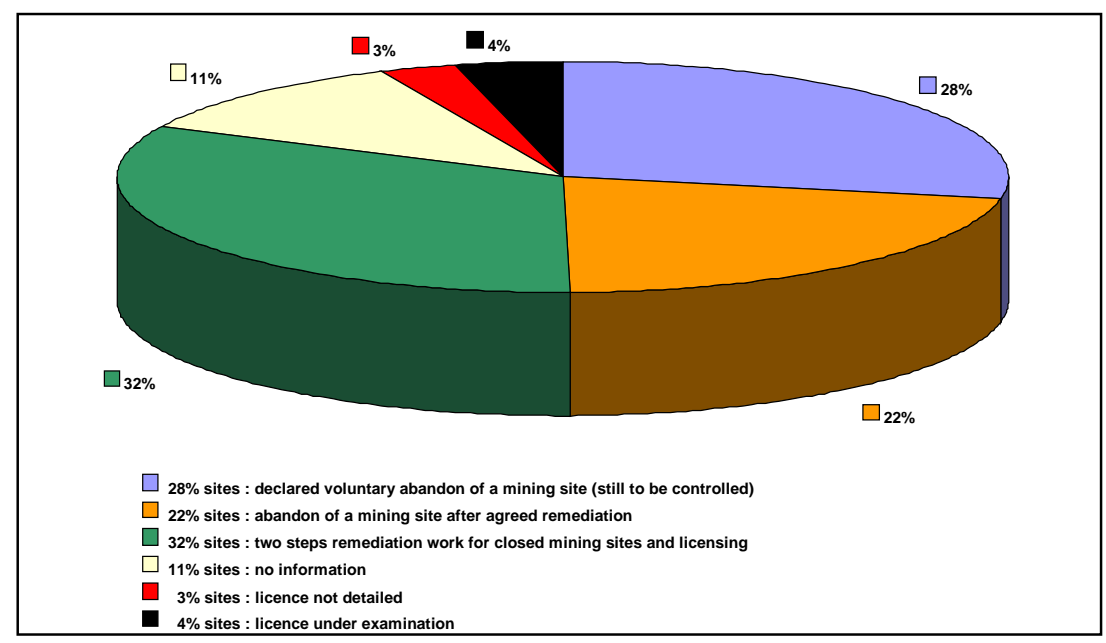

Figure 7. Distribution of the sites according to their status at the end of operation.

\section{MIMAUSA DATABASE}

The inventory gives information on a limited set of data. The complete project (minimum 2 years) plans to build a computerized database giving as much information as possible on:

- The site location and situation in its environment, a few words on the geological context and mineralization, surface and underground water, maps, ...

- The history of the site: dates for the different steps and details on the different operations (mining, milling, wastes disposal facilities and water treatment plant during and specially after remediation),

- The administrative situation: history of the mining leases and the owners in the past, details on the various letters from the administration (authorisations) and licences during operation and, after remediation, as far as possible, the set of administrative documentation as scanned files,

- Details on the remediation implemented on the sites and the facilities at the end of operation,

- Some details on the monitoring going on after the remediation and main results along the history of the site, and from various origins (continuous monitoring by the operator as well as by IRSN and results of verification measurement and sampling during visits on the sites).

Site visits are intended for the second part of MIMAUSA ("specific studies"). This second part of the job might conclude and suggest changes in the monitoring of the sites.

\section{CONCLUSION}

The inventory was built in close cooperation with the main operator (AREVA (COGEMA)). It is the basis of this overview and it is the most comprehensive attempt by IRSN to gather data on the whole French uranium-mining sector.

It is going to be regularly updated, made public on http://www.irsn.org/ and enlarged as a database giving IRSN a tool to assist the Ministry of Ecology and the Ministry of Industry as part of their mission for the long-term stewardship. 